\title{
Independent associations between arterial bicarbonate, apnea severity and hypertension in obstructive sleep apnea
}

\author{
Davoud Eskandari ${ }^{1}$, Ding Zou ${ }^{1 *}$ (D), Ludger Grote ${ }^{1}$, Hartmut Schneider ${ }^{2}$, Thomas Penzel ${ }^{3,4}$ and Jan Hedner ${ }^{1}$
}

\begin{abstract}
Background: Obstructive sleep apnea is characterized by intermittent hypoxia and hypercapnia. $\mathrm{CO}_{2}$ production, transport and elimination are influenced by the carbonic anhydrase enzyme. We hypothesized that elevated standard bicarbonate, a proxy for increased carbonic anhydrase activity, is associated with apnea severity and higher blood pressure in patients with obstructive sleep apnea.

Methods: A retrospective analysis of a sleep apnea cohort $(n=830)$ studied by ambulatory polygraphy. Office systolic/diastolic blood pressure, lung function, and arterial blood gases were assessed during daytime.

Results: Arterial standard bicarbonate was increased with apnea severity (mild/moderate/severe $24.1 \pm 1.8,24.4 \pm 1.7$ and $24.9 \pm 2.9 \mathrm{mmol} / \mathrm{l}$, respectively, Kruskal-Wallis test $p<0.001)$. Standard bicarbonate was independently associated with apnea hypopnea index after adjustment for sex, age, body mass index, smoking, alcohol, hypertension, $\mathrm{pO}_{2}$ and $\mathrm{pCO}_{2}$ (standard bicarbonate quartile 1 vs. quartile 4, $\beta=10.6, p<0.001$ ). Log-transformed standard bicarbonate was associated with a diagnosis of hypertension or diastolic blood pressure but not systolic blood pressure adjusting for cofounders ( $p=0.007,0.048$ and 0.45 , respectively).

Conclusions: There was an independent association between sleep apnea severity and arterial standard bicarbonate. The link between high standard bicarbonate and daytime hypertension suggests that carbonic anhydrase activity may constitute a novel mechanism for blood pressure regulation in sleep apnea.
\end{abstract}

Keywords: Acid base, Blood pressure, Carbonic anhydrase, Hypercapnia, Obstructive sleep apnea

\section{Background}

Obstructive sleep apnea (OSA) is associated with intermittent oscillations of oxygen and carbon dioxide $\left(\mathrm{CO}_{2}\right)$ during the sleeping period. The severity of these changes is determined not only by altered ventilation during the apneic cycle, but also by the extent of tissue oxidative metabolism and tissue deposition of $\mathrm{CO}_{2}$ in the body [1]. $\mathrm{CO}_{2}$ production, transport and elimination are influenced by the activity of the enzyme carbonic anhydrase (CA). CA catalyzes the inter-conversion of $\mathrm{CO}_{2}$ and water into carbonic acid, protons and bicarbonate $\left(\mathrm{StHCO}_{3}{ }^{-}\right)$[2]. Hence, this enzyme plays an important role for the maintenance of blood gas stability in OSA.

\footnotetext{
* Correspondence: zou.ding@lungall.gu.se

${ }^{1}$ Center for Sleep and Vigilance Disorders, Department of Internal Medicine and Clinical Nutrition, Sahlgrenska Academy, University of Gothenburg,

Medicinaregatan 8B, Box 421SE-40530 Gothenburg, Sweden

Full list of author information is available at the end of the article
}

We have previously demonstrated an association between whole blood CA activity and the severity of OSA [3]. Further we hypothesized that arterial $\mathrm{StHCO}_{3}{ }^{-}$ concentration (a surrogate for CA activity) was elevated in relation to the degree of disordered breathing in OSA patients.

Hypertension development in OSA has been related to multiple mechanisms including increased sympathetic autonomic activity, endothelial dysfunction and modified activity of the renin-angiotensin aldosterone system [4]. Hypoxic and/or hypercapnic chemoreceptor reflex activation and modified baroreflex sensitivity have also been implied in OSA related hypertension [5]. In fact, hypercapnia may be of greater importance than hypoxia in causing sympathetically induced blood pressure elevation and vascular resistance in OSA [6]. In addition, results from in-vitro and in-vivo protocols suggest an 
association between CA activity and blood pressure controlling mechanisms [7, 8]. Hypertensive OSA patients reduced blood pressure in response to pharmacological inhibition of CA [9] and acetazolamide partially prevented blood pressure elevation in OSA patients moving from low- to high altitude [10]. Whether the surrogate for $\mathrm{CA}$ activity, $\mathrm{StHCO}_{3}^{-}$, is associated with hypertension in OSA patients independent of sleep apnea severity has never been investigated. In the current study, we aimed to address the association between $\mathrm{StHCO}_{3}{ }^{-}$and OSA activity as well as to examine a possible link between $\mathrm{StHCO}_{3}{ }^{-}$and hypertension.

\section{Methods}

\section{Study population and protocol}

The study cohort $(n=1656)$ consisted patients successively referred to the Marburg Sleep Disorders Center between 1989-1992 due to clinical symptoms of sleep related breathing disorder [11]. Patients were systematically investigated to study the relationship between OSA, lung function and hypertension. In detail, anthropometric data such as age, sex, body mass index (BMI) were collected. Alcohol consumption, smoking habits along with signs of sleep disorder, such as excessive daytime sleepiness, snoring and insomnia were also recorded. In addition, a medical history including clinical diagnoses and concomitant medication, with particular focus on known and/or treated hypertension, was obtained. Daytime arterial blood samples for determination of blood gases, including $\mathrm{StHCO}_{3}^{-}$, were collected. A home sleep study and lung function test using full body plethysmography (Jäger, Würzburg, Germany) were undertaken. All patients gave their written consent for participation in the study according to the contemporary regulations for medical research at the Marburg University, Marburg, Germany in $1989-1992$.

\section{Exclusion criteria for data analysis}

Three hundred ninety six patients were excluded from the analysis due to missing anthropometric data $(n=210)$, blood gas data $(n=163)$, lung function test data $(n=20)$ and sleep data $(n=3)$. Patients with obesity hypoventilation syndrome $\left(n=38\right.$, defined as BMI $>30 \mathrm{~kg} / \mathrm{m}^{2}$ with a $\mathrm{pCO}_{2}>6 \mathrm{kPa}$ ), chronic obstructive pulmonary disease, defined as the ratio of forced expiratory volume in $1 \mathrm{~s}$ to forced vital capacity of less than 0.70 , were excluded $(n=163)$. In addition, 12 respiratory failure patients with arterial blood gas $\mathrm{pO}_{2} \leq 8.0 \mathrm{kPa}$ and/or $\mathrm{pCO}_{2} \geq 6.5 \mathrm{kPa}$ were excluded. Finally, non-OSA patients with apnea hypopnea index (AHI) $<5 \mathrm{n} / \mathrm{h}$ were excluded from the analysis $(n=217)$ and a total of 830 patients were included in the data analysis (Fig. 1).
Blood pressure, blood gas and blood sample assessment Systolic (SBP) and diastolic (DBP) blood pressures were obtained with the patient in a sitting position after a minimum of 10 minutes rest, between 9.00 and 11.00 a.m., using the World Health Organization standard protocol [12]. Heart rate defined as beats per minute was determined in the sitting position by pulse wave palpation. Blood samples were obtained at the morning following an overnight fast. A blood gas analysis (samples obtained at noon) was performed using a RADIOMETER - gas analyzer (Radiometer, Copenhagen, Denmark).

\section{Definition of hypertension}

Hypertension was defined as patients with a previous positive history of diagnosed hypertension and/or on ongoing hypertensive medication. Normotension was defined as patients with no previous hypertensive medical history and no ongoing anti-hypertensive treatment.

\section{Sleep study}

All patients underwent unattended home monitoring of nocturnal breathing on two consecutive nights using the MESAM 4 polygraphy device (MAP ${ }^{\circ}$, Munich, Germany). The polygraphy system was applied in the afternoon for a recording span between 6.00 p.m. and 8.00 a.m. Time to bed, lights out, final awakening, longer periods of sleep interruption and estimated sleep time were assessed using a patient diary. The first night was an adaptation night and the AHI value used for calculation in this study was obtained from the second night. Only when the recording was technically insufficient ( $<10 \%$ of recordings) or the subjective sleep time was $<5$ hours $(<1 \%$ of recordings), then AHI was obtained from the first night.

The MESAM 4 device records oxygen saturation using finger pulse oximetry, snoring using an electret-miniature microphone placed over the larynx, beat to beat heart rate analysis using ECG, and body position using a circular sensor taped just below the sternum. It is a validated sleep diagnostic instrument for clinical and epidemiological studies [13, 14]. In the current study, apnea hypopnea events were determined visually using the previously described methods of MESAM 4 evaluation [15]. In detail, events were first scored with a concomitant oxygen desaturation of $\geq 4 \%$ from baseline. Subsequently, the scorers edited this information by checking the heart rate (significant drop and reduced variability when going to bed, abrupt increase and plateau after final awakening), movement artefacts, and body position signal (e.g. change from upright to supine position). Estimated sleep time was determined based on the information from the sleep diary (time going to bed, lights out, final awakening, lights on, longer periods of sleep interruption). Finally, AHI was calculated as the number of apnea/hypopnea events per hour of edited recording time. OSA severity was defined as 


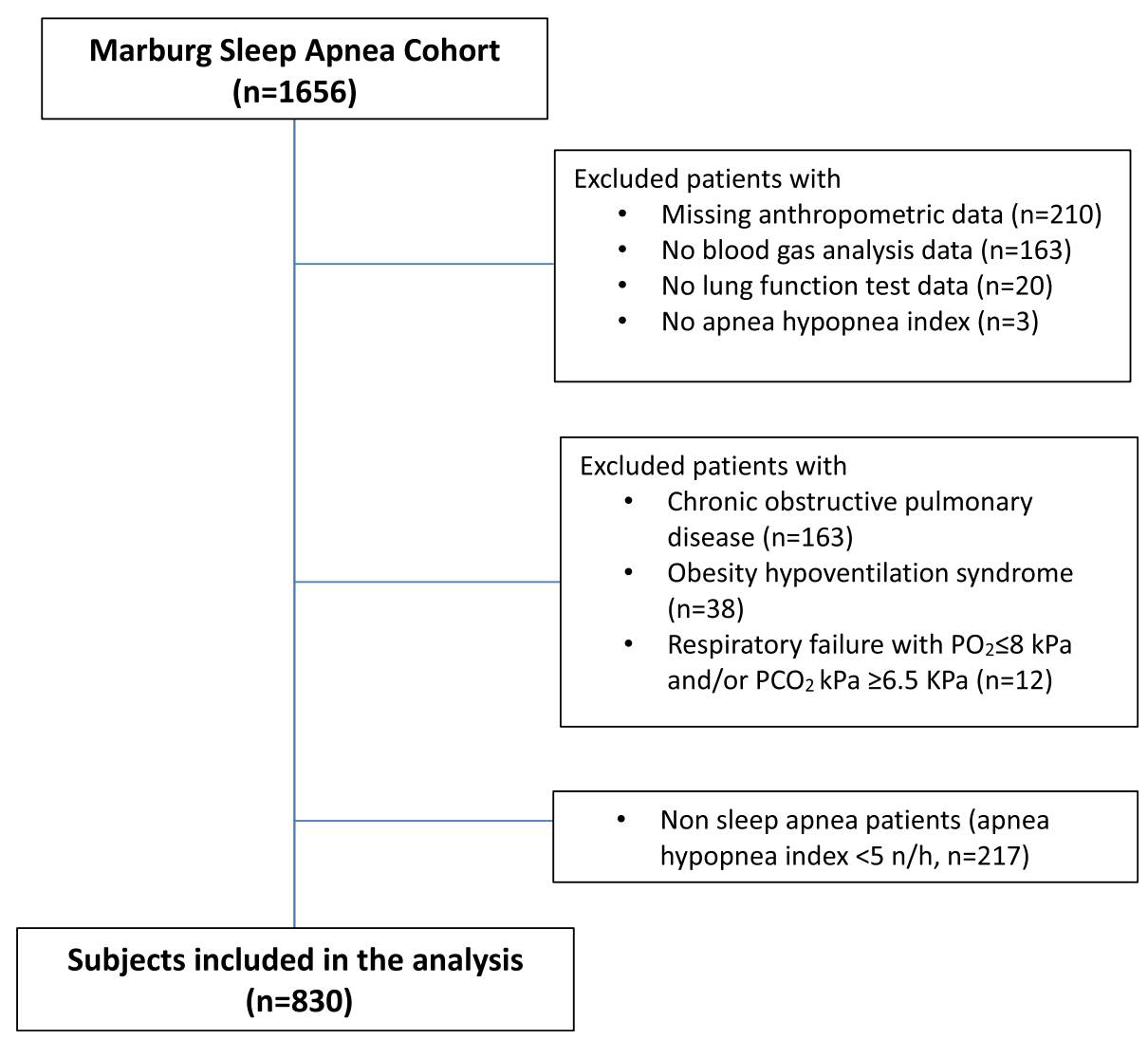

Fig. 1 Study flow chart

mild $(5 \leq \mathrm{AHI}<15 \mathrm{n} / \mathrm{h})$, moderate $(15 \leq \mathrm{AHI}<30 \mathrm{n} / \mathrm{h})$ and severe (AHI $\geq 30 \mathrm{n} / \mathrm{h})$.

\section{Statistics}

Statistical analysis was conducted using IBM SPSS 20 (SPSS Inc, Chicago, USA). Kolmogorov-Simirnov test was used to determine the distribution of the data. Spearman correlation was used to study the association between arterial $\mathrm{StHCO}_{3}{ }^{-}$and AHI, SBP and DBP. Fisher exact test was used to compare catergory variables. Depending on data distribution, differences across apnea severity groups and $\mathrm{StHCO}_{3}{ }^{-}$quartiles were assessed by one-way analysis of variance (ANOVA) or KruskalWallis test. Multivariate generalized linear models were used to address the independent association between StHCO ${ }_{3}{ }^{-}$, apnea severity and hypertension. $\mathrm{StHCO}_{3}{ }^{-}$was log-transformed in order to enable parametric statistics. Data are presented as mean \pm SD. A $p$-value $<0.05$ was considered statistically significant.

\section{Results}

Study population and blood gas characteristics

In total 830 patients were included in the study (93.3\% men, age $51 \pm 10$ years, BMI $30 \pm 5 \mathrm{~kg} / \mathrm{m}^{2}$, AHI $32 \pm 24 \mathrm{n} / \mathrm{h}$ ).
Hypertension was prevalent in $53.3 \%$ of the patients and increased with OSA severity class. Patient characteristics in different OSA severity classes are shown in Table 1. There was a small but significant change in arterial blood gases in higher AHI severity classes. Mean $\mathrm{pO}_{2}$ decreased with approximately $0.5 \mathrm{kPa}$ from mild to severe OSA patients $(p<0.001)$. Mean $\mathrm{pCO}_{2}$ increased slightly in patients with severe OSA $(p=0.046)$. The $\mathrm{pH}$ and lung function values did not change along with severity class of OSA.

\section{The association between $\mathrm{StHCO}_{3}^{-}$and sleep apnea}

Arterial $\mathrm{StHCO}_{3}{ }^{-}$was significantly correlated with $\mathrm{pCO}_{2}$ (Spearman correlation $r=0.75, p<0.001$, Additional file 1: Figure S1). StHCO3 ${ }^{-}$increased across OSA severity classes although the mean absolute magnitude of change was moderate (Kruskal-Wallis test, $p<0.001$, Table 1 ). The association between OSA severity and $\mathrm{StHCO}_{3}^{-}$was observed in hypertensive OSA patients but not in normotensive OSA patients (Fig. 2). $\mathrm{StHCO}_{3}{ }^{-}$was positively correlated with AHI (Spearman correlation $r=0.16, p<0.001$, Additional file 1: Figure S2). Mean AHI increased from $27 \pm 21 \mathrm{n} / \mathrm{h}$

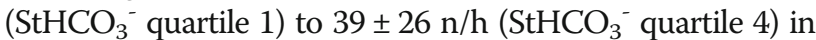
the whole population $(p<0.001$, Table 2$)$. A similar but 
Table 1 Patient characteristics across sleep apnea severity

\begin{tabular}{|c|c|c|c|c|}
\hline & $\begin{array}{l}\text { Mild } \\
n=272\end{array}$ & $\begin{array}{l}\text { Moderate } \\
n=211\end{array}$ & $\begin{array}{l}\text { Severe } \\
n=347\end{array}$ & $\begin{array}{l}P \text { value } \\
\text { (ANOVA) }\end{array}$ \\
\hline Male sex (\%) & 89 & 95 & 96 & $0.001^{*}$ \\
\hline Age (yrs) & $50(11)$ & $51(9)$ & $52(9)$ & 0.10 \\
\hline Body mass index $\left(\mathrm{kg} / \mathrm{m}^{2}\right)$ & $28(4)$ & $29(4)$ & $32(6)$ & $<0.001$ \\
\hline Smoking (\%) & 28 & 29 & 28 & $0.98^{*}$ \\
\hline Systolic BP (mmHg) & $141(18)$ & $145(21)$ & $152(22)$ & $<0.001$ \\
\hline Diastolic BP (mmHg) & $91(12)$ & $94(12)$ & $97(13)$ & $<0.001$ \\
\hline Heart rate (bpm) & $71(11)$ & $71(10)$ & $77(11)$ & $<0.001$ \\
\hline Hypertension (\%) & 40.4 & 51.7 & 64.3 & $<0.001^{*}$ \\
\hline Apnea hypopnea index $(n / h)$ & $9(3)$ & $22(4)$ & $55(18)$ & $<0.001$ \\
\hline $\mathrm{FEV}_{1} / \mathrm{FVC}(\%)$ & $82(6)$ & $81(5)$ & $81(6)$ & 0.33 \\
\hline $\mathrm{pH}$ & $7.41(0.02)$ & $7.42(0.02)$ & $7.42(0.03)$ & 0.075 \\
\hline $\mathrm{pO}_{2}(\mathrm{kPa})$ & $10.8(1.0)$ & $10.7(1.0)$ & $10.3(1.0)$ & $<0.001$ \\
\hline $\mathrm{pCO}_{2}(\mathrm{kPa})$ & $5.06(0.40)$ & $5.07(0.36)$ & $5.13(0.39)$ & 0.046 \\
\hline $\mathrm{StHCO}_{3}^{-}(\mathrm{mmol} / \mathrm{l})$ & $24.1(1.8)$ & $24.4(1.7)$ & $24.9(2.9)$ & $<0.001^{\#}$ \\
\hline
\end{tabular}

*Fisher exact test; ${ }^{*}$ Kruskal-Wallis test; $\mathrm{BP}=$ blood pressure; bpm = beat per minute; $\mathrm{FEV} 1 / \mathrm{FVC}=$ forced expiratory volume at 1 second interval/forced vital capacity; $\mathrm{pO}_{2}=$ arterial partial pressure of oxygen; $\mathrm{pCO}_{2}=$ arterial partial pressure of carbon dioxide; $\mathrm{StHCO}_{3}{ }^{-}=$arterial standard bicarbonate

nonsignificant trend was found in OSA patients without a hypertension diagnosis $(n=388, p=0.094$, Additional file 1: Table S1). In a generalized linear model controlling for sex, age, BMI, smoking, alcohol consumption, $\mathrm{pO}_{2}, \mathrm{pCO}_{2}$ and hypertension status, $\mathrm{StHCO}_{3}{ }^{-}$was independently associated with AHI (Q1 vs. Q4 $\beta=10.6, p<0.001$, Table 3 ).

\section{Association between $\mathrm{StHCO}_{3}{ }^{-}$, hypertension and office} blood pressure

$\mathrm{StHCO}_{3}{ }^{-}$was higher in hypertensive $(n=442)$ compared with normotensive $(n=388)$ patients $(24.9 \pm 2.7$ vs. $24.1 \pm 1.9 \mathrm{mmol} / \mathrm{l}, p<0.001)$. The percentage of patients with a clinical hypertension diagnosis is $46.8,49.8,54.3$ and 62.7\% respectively across $\mathrm{StHCO}_{3}^{-}$quartiles (Q1 to Q4)

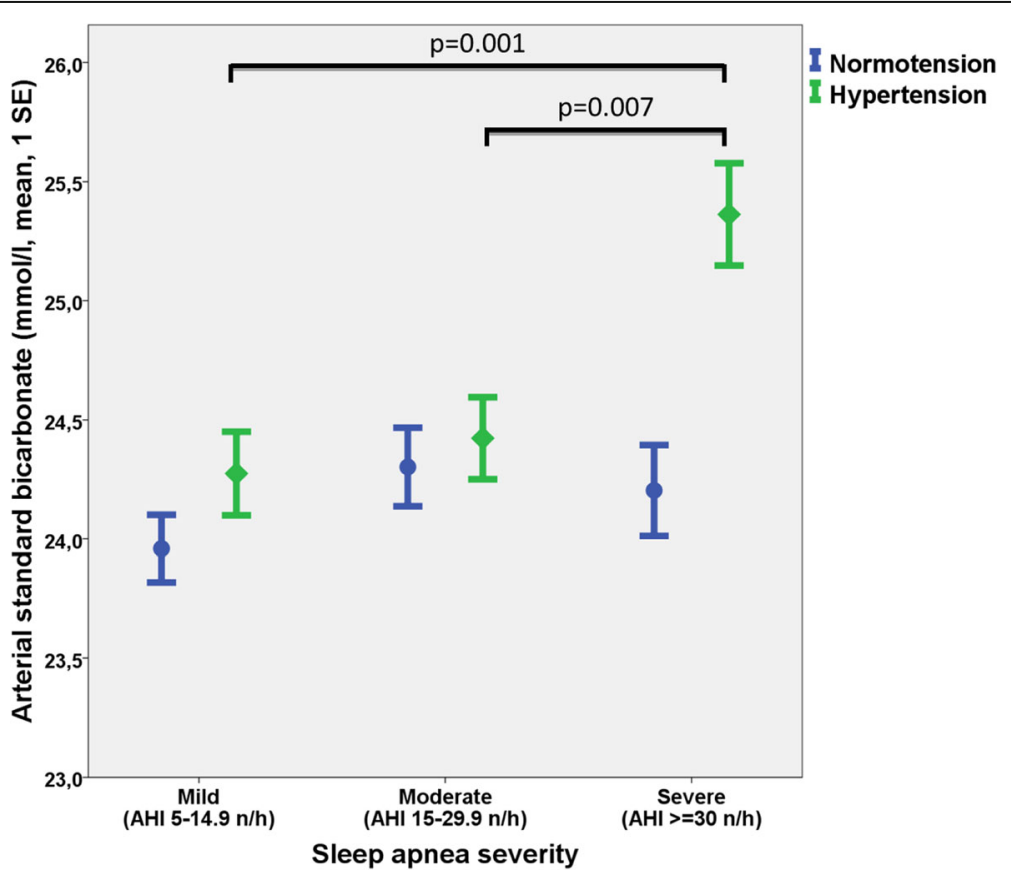

Fig. 2 Arterial standard bicarbonate concentrations by sleep apnea severity class 
Table 2 Patient characteristics across $\mathrm{StHCO}_{3}{ }^{-}$quartiles $(n=830)$

\begin{tabular}{|c|c|c|c|c|c|}
\hline & $\begin{array}{l}\text { Q1 } \\
{[17.5-23.2] \mathrm{mmol} / \mathrm{l}}\end{array}$ & $\begin{array}{l}\mathrm{Q} 2 \\
{[23.3-24.5] \mathrm{mmol} / \mathrm{l}}\end{array}$ & $\begin{array}{l}\text { Q3 } \\
{[24.6-25.7] \mathrm{mmol} / \mathrm{l}}\end{array}$ & $\begin{array}{l}\text { Q4 } \\
{[25.8-46.1] \mathrm{mmol} / \mathrm{l}}\end{array}$ & $\begin{array}{l}P \text { value } \\
\text { (ANOVA) }\end{array}$ \\
\hline Male sex (\%) & 92 & 92 & 97 & 93 & $0.081^{*}$ \\
\hline Age (yrs) & $51(10)$ & $51(9)$ & $49(9)$ & $52(10)$ & 0.058 \\
\hline Body mass index $\left(\mathrm{kg} / \mathrm{m}^{2}\right)$ & $29(5)$ & $30(5)$ & $30(5)$ & $31(5)$ & 0.071 \\
\hline Smoking (\%) & 26 & 30 & 33 & 25 & $0.27^{*}$ \\
\hline Systolic BP (mmHg) & $144(19)$ & $144(21)$ & $147(22)$ & $150(22)$ & 0.006 \\
\hline Diastolic BP (mmHg) & $92(11)$ & $93(13)$ & $95(13)$ & $96(13)$ & 0.005 \\
\hline Heart rate (bpm) & $73(11)$ & $72(11)$ & $73(11)$ & $75(12)$ & 0.065 \\
\hline Hypertension (\%) & 46.8 & 49.8 & 54.3 & 62.7 & $0.007^{*}$ \\
\hline Apnea hypopnea index (n/h) & $27(21)$ & $31(22)$ & $30(24)$ & $39(26)$ & $<0.001$ \\
\hline $\mathrm{FEV}_{1} / \mathrm{FVC}(\%)$ & $82(6)$ & $81(6)$ & $82(6)$ & $82(6)$ & 0.90 \\
\hline $\mathrm{pH}$ & $7.41(0.03)$ & $7.41(0.02)$ & $7.42(0.02)$ & $7.43(0.02)$ & $<0.001$ \\
\hline $\mathrm{pO}_{2}(\mathrm{kPa})$ & $10.9(1.1)$ & $10.6(0.9)$ & $10.6(1.0)$ & $10.2(1.0)$ & $<0.001$ \\
\hline $\mathrm{pCO}_{2}(\mathrm{kPa})$ & $4.67(0.30)$ & $5.03(0.24)$ & $5.26(0.24)$ & $5.43(0.25)$ & $<0.001$ \\
\hline $\mathrm{StHCO}_{3}^{-}(\mathrm{mmol} / \mathrm{l})$ & $22.0(1.1)$ & $23.9(0.4)$ & $25.2(0.3)$ & $27.2(2.6)$ & - \\
\hline
\end{tabular}

*Fisher exact test; $B P$ blood pressure, bpm beat per minute, $F E V 1 / F V C$ forced expiratory volume at 1 second interval/forced vital capacity, $p \mathrm{O}_{2}$ arterial partial pressure of oxygen, $\mathrm{pCO}_{2}$ arterial partial pressure of carbon dioxide, $\mathrm{StHCO}_{3}{ }^{-}$arterial standard bicarbonate

$(p=0.007$, Table 2). Both OSA severity and higher $\mathrm{StHCO}_{3}{ }^{-}$were associated with increased prevalence of hypertension in this population (Fig. 3). In a generalized linear model controlling for sex, age, BMI, smoking, alcohol consumption, $\mathrm{pO}_{2}, \mathrm{pCO}_{2}$ and apnea severity, LogStHCO ${ }_{3}{ }^{-}$was independently associated with a clinical diagnosis of hypertension $(\beta=8.0$, SE 3.0, 95\% CI [2.1-13.8], $p=0.007$, Table 4).

An additional analysis was performed to study the relationship between $\mathrm{StHCO}_{3}^{-}$and office blood pressure. $\mathrm{StHCO}_{3}{ }^{-}$was modestly correlated with SBP and DBP (Spearman correlation, $r=0.10$ and $0.12, p=0.003$ and $<0.001$, respectively). In generalized linear models with SBP and DBP, respectively, as dependent variables, a positive independent association was found between
LogStHCO ${ }_{3}{ }^{-}$and DBP $(\beta=27.6, \mathrm{SE} 14.0,95 \% \mathrm{CI}[0.2-55.0]$, $p=0.048)$ but not with SBP $(\beta=17.1$, SE $22.3,95 \% \mathrm{CI}$ [-26.7-60.9], $p=0.45)$ after adjustment for sex, age, BMI, smoking, alcohol usage, $\mathrm{pO}_{2}, \mathrm{pCO}_{2}$ and apnea severity (Additional file 1: Table S2 and S3).

\section{Discussion}

In this large cross sectional study of a predominantly male clinical sleep apnea cohort, we established an independent association between wake arterial $\mathrm{StHCO}_{3}{ }^{-}$concentration and the intensity of sleep apnea. In addition, there was an independent association between $\mathrm{StHCO}_{3}^{-}$ and hypertension as well as daytime office DBP. Our data suggest that mechanisms related to acid-base balance may link to the expression of OSA and its

Table 3 Generalized linear model investigating the association between apnea hypopnea index and arterial bicarbonate quartiles controlled for confounding factors

\begin{tabular}{|c|c|c|c|c|}
\hline & Beta value & Standard error & 95\% confidence interval & $P$-value \\
\hline Male sex & 8.28 & 3.03 & $2.35-14.21$ & 0.006 \\
\hline Age (years) & 0.12 & 0.08 & $-0.05-0.28$ & n.s. \\
\hline Body mass index $\left(\mathrm{kg} / \mathrm{m}^{2}\right)$ & 1.45 & 0.16 & $1.14-1.76$ & $<0.001$ \\
\hline Smoking & 4.37 & 1.71 & $1.03-7.72$ & 0.01 \\
\hline Alcohol & 2.00 & 1.58 & $-1.11-5.10$ & n.s. \\
\hline Hypertension & 4.89 & 1.54 & $1.86-7.92$ & 0.002 \\
\hline $\mathrm{PO}_{2}(\mathrm{kPa})$ & -0.36 & 0.10 & $-0.57--0.16$ & 0.001 \\
\hline $\mathrm{PCO}_{2}(\mathrm{kPa})$ & -0.52 & 0.38 & $-1.27-0.23$ & n.s. \\
\hline $\mathrm{StHCO}_{3}{ }^{-} \mathrm{Q} 2$ vs. Q1 & 4.76 & 2.29 & $0.27-9.25$ & 0.038 \\
\hline $\mathrm{StHCO}_{3}^{-} \mathrm{Q} 3$ vs. Q1 & 4.34 & 2.67 & $-0.90-9.57$ & n.s. \\
\hline $\mathrm{StHCO}_{3}{ }^{-} \mathrm{Q} 4$ vs. Q1 & 10.63 & 3.00 & $4.76-16.51$ & $<0.001$ \\
\hline
\end{tabular}




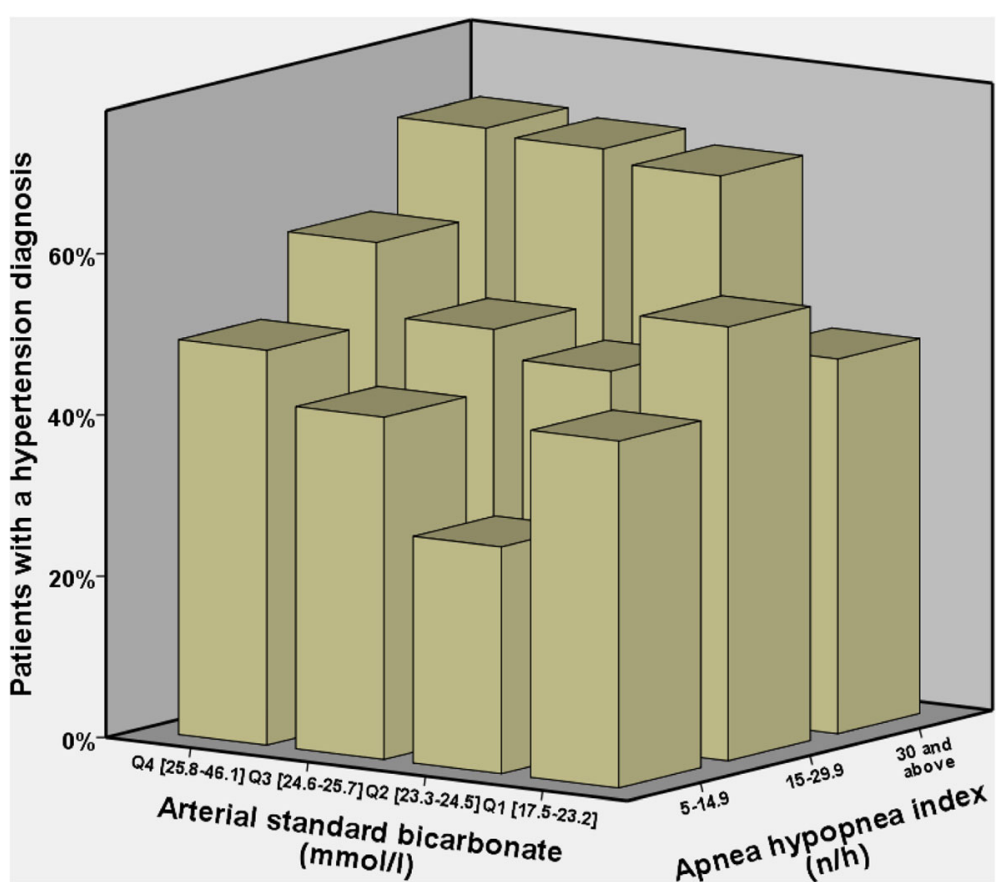

Fig. 3 Prevalence of hypertension by sleep apnea severity and arterial standard bicarbonate quartile

cardiovascular sequels. Given the strong inter-correlation between $\mathrm{StHCO}_{3}{ }^{-}$and $\mathrm{CA}$ activity we speculate that $\mathrm{CA}$ activity is involved in blood pressure regulation in OSA patients.

Elevated $\mathrm{StHCO}_{3}^{-}$concentration has been used as marker for hypercapnia in patients with respiratory disorders such as obesity-hypoventilation syndrome (OHS) and pre-clinical OHS [16, 17]. The association between $\mathrm{StHCO}_{3}{ }^{-}$and OSA is less well studied. In this study we excluded patients with chronic obstructive pulmonary disease and OHS based on information of a goldstandard evaluation of respiratory function and a blood gas analysis. Our data unequivocally demonstrated a dose dependent association between OSA and daytime arterial $\mathrm{StHCO}_{3}{ }^{-}$concentration in this group of patients without a chronic respiratory disorder. Although the magnitude of the $\mathrm{StHCO}_{3}{ }^{-}$elevation across the spectrum of OSA severity may be considered as rather limited, the association was statistically significant and remained after extensive control of important confounders. To our knowledge this is the first study to demonstrate this association in a well characterized clinical OSA cohort. The exact mechanism behind this finding in OSA remains unknown. Severe OSA may lead to mild nocturnal hypercapnia. The long term effect of OSA on $\mathrm{PCO}_{2}$ (i.e. StHCO3 ${ }^{-}$) is determined by the net change of $\mathrm{CO}_{2}$ over each cycle of apnea/hyperventilation and asymmetry in how the rise and fall of $\mathrm{CO}_{2}$ affects the kidney. It is

Table 4 Generalized linear model investigating the association between hypertension status and log-transformed arterial bicarbonate controlled for confounding factors

\begin{tabular}{lcccc}
\hline & Beta value & Standard error & 95\% confidence interval & $P$-value \\
\hline Male sex & 0.33 & 0.31 & $-0.28-0.94$ & n.s. \\
Age (years) & 0.019 & 0.009 & $0.002-0.036$ & 0.025 \\
Body mass index $\left(\mathrm{kg} / \mathrm{m}^{2}\right)$ & 0.09 & 0.02 & $0.06-0.13$ & $<0.001$ \\
Smoking & -0.35 & 0.17 & $-0.69--0.02$ & 0.039 \\
Alcohol & 0.16 & 0.16 & $-0.15-0.47$ & $\mathrm{n}$ \\
Moderate vs. mild OSA & 0.33 & 0.19 & $-0.05-0.70$ & 0.088 \\
Severe vs. mild OSA & 0.52 & 0.18 & $0.16-0.88$ & 0.004 \\
$\mathrm{PO}_{2}(\mathrm{kPa})$ & -0.01 & 0.01 & $-0.04-0.01$ & $\mathrm{n}$ \\
$\mathrm{PCO}_{2}(\mathrm{kPa})$ & -0.02 & 0.04 & $-0.09-0.05$ & $\mathrm{n}$ \\
$\mathrm{LogStHCO}_{3}^{-}$ & 7.96 & 2.97 & $2.15-13.77$ & 0.007 \\
\hline
\end{tabular}


likely that changes of CA activity can modulate the transition of obstructive apnea/ventilation cycle and influence the increase in StHCO3 ${ }^{-}$[18-20]. We therefore propose that transient hypercapnic episodes during sleep in patients with more severe OSA lead to increased renal reabsorption of $\mathrm{StHCO}_{3}{ }^{-}$and/or that a chronic increase of $\mathrm{StHCO}_{3}{ }^{-}$production [18] is induced by high or possibly even up-regulated CA activity.

$\mathrm{StHCO}_{3}{ }^{-}$concentration is known to be influenced by CA enzyme activity. One major function of this enzyme includes the catalysis of the interconversion of bicarbonate and protons into $\mathrm{CO}_{2}$ and water for subsequent removal of $\mathrm{CO}_{2}$ via the respiratory apparatus [2]. In OSA, repetitive changes in $\mathrm{pCO}_{2}$ may induce $\mathrm{CA}$ enzyme activity and increase arterial $\mathrm{StHCO}_{3}{ }^{-}$concentration. Alternatively, anaerobic metabolism and respiratory acidosis following intermittent hypoxia may induce an increased activity of enzymes and transporters involved in cellular $\mathrm{pH}$ regulation and erythrocyte acid-base handling [21]. In this manner both hypercapnia and hypoxia may contribute to increased CA activity in patients with OSA. Along these lines it is worth mentioning that $\mathrm{CA}$ enzyme inhibition has been shown to reduce $\mathrm{StHCO}_{3}{ }^{-}$concentration in patients with sleep disordered breathing $[9,22,23]$ and that we previously have demonstrated an association between CA activity and the severity of OSA [3].

A particularly interesting finding in the current study was the strong association between $\mathrm{StHCO}_{3}{ }^{-}$and hypertension status or diastolic blood pressure. It may be argued that this association could be explained by the wellestablished link between OSA and hypertension [5]. However, our data suggest that $\mathrm{StHCO}_{3}^{-}$was linked to hypertension independently of the AHI. Only few studies have addressed the possible association between $\mathrm{StHCO}_{3}{ }^{-}$and hypertension. In a population based study of middle-aged non-obese females, lower plasma $\mathrm{StHCO}_{3}{ }^{-}$was associated with an elevated incidence of hypertension [24]. A small experimental study of oral sodium bicarbonate induced approximately $5 \mathrm{mmHg}$ reduction of systolic blood pressure [25] whereas other studies did not [26, 27]. However, these studies did not address subjects with the acute blood gas changes that characterize the OSA condition. In fact, our data suggest that the association between hypertension and $\mathrm{StHCO3}^{-}$is mainly confined to subjects with severe OSA. As previously stated several different mechanisms, including increased renal re-absorption of $\mathrm{StHCO}_{3}{ }^{-}$, extended $\mathrm{CO}_{2}$ loading and/or increased CA activity, could all have increased of $\mathrm{StHCO}_{3}{ }^{-}$in OSA $[3,18,28]$. In fact, a positive association between whole blood CA activity and blood pressure has been reported [3]. In addition, CA inhibition by zonisamide in OSA patients reduced both the AHI and the systolic blood pressure [9]. The CA inhibitor acetazolamide and hydrochlorothiazide induced vasodilation by an activation of calcium activated potassium channels [7, 29] or via a modulation of nitric oxide metabolism activity [30]. It cannot be excluded that the increase of $\mathrm{StHCO}^{-}$ in our study might have resulted from the effect of hypertension on renal StHCO3 ${ }^{-}$reabsorption. However, this is less likely the explanation considering that $\mathrm{StHCO}^{-}$was elevated only in the severe OSA group with hypertension. We therefore propose that increased CA activity in OSA may provide a novel intermediary mechanism for hypertension development in OSA.

Our study has both strengths and limitations. First, this large predominently male clinical OSA cohort applied a rigorous and unique control of important confounders of $\mathrm{StHCO}_{3}{ }^{-}$like arterial blood gas samples and pulmonary function tests. Second, blood pressure and hypertension status were carefully assessed during daytime as part of the study protocol. Sleep disordered breathing was assessed with a contemporary polygraphy recording device on two consecutive nights in order to exclude inaccuracy of the AHI value due to a first night effect [31]. Weaknesses include a lack of quantitative data on overnight hypoxic events like oxygen desaturation in the multivariate analyses. However, nocturnal hypoxic exposure was captured as $4 \%$ oxygen desaturation events that were used for compution of AHI. Another weakness in this study is the lack of detailed information on the type of antihypertensive medication. It cannot be excluded that prescribed antihypertensive medication, e.g. diuretics such as hydrochlorothiazide, might have influenced the association between $\mathrm{StHCO}_{3}{ }^{-}$ and blood pressure although the influence of thiazides on $\mathrm{StHCO}_{3}{ }^{-}$is likely to be very limited [32]. Information on CA was not available in this retrospective study. Finally, the cross sectional design of our study does not allow conclusions about the causality of the demonstrated associations.

\section{Conclusions}

It is concluded that $\mathrm{StHCO}_{3}{ }^{-}$concentration was independently associated with $\mathrm{AHI}$, a hypertension diagnosis and office diastolic blood pressure in OSA patients. The potential causal relationship (s) behind these associations remain unclear. Higher $\mathrm{StHCO}_{3}{ }^{-}$was linked to more intense OSA indicating that high or upregulated $\mathrm{CA}$ activity is associated with OSA. In addition, $\mathrm{StHCO}_{3}{ }^{-}$ was associated with hypertension independent of sleep apnea suggesting a novel CA-related mechanism for blood pressure regulation in hypertensive OSA patients.

\section{Additional file}

Additional file 1: Table S1. Normotensive patient characteristics across StHCO3 ${ }^{-}$quartiles $(n=388)$. Table S2. Association between $\mathrm{LogStHCO}_{3}{ }^{-}$ and systolic blood pressure in a generalized linear model. Table S3. Association between $\mathrm{LogStHCO}_{3}{ }^{-}$and diastolic blood pressure in a generalized linear model. Figure $\mathbf{S} 1$. Relationship between $\mathrm{pCO}_{2}$ and $\mathrm{stHCO}_{3}{ }^{-}$(Spearman correlation). Figure S2. Relationship between apnea hypopnea index and $\mathrm{stHCO}_{3}{ }^{-}$(Spearman correlation). (DOCX 107 kb) 


\section{Abbreviations}

AHI: Apnea hypopnea index; ANOVA: One-way analysis of variance; BMI: Body mass index; CA: Carbonic anhydrase; $\mathrm{CO}_{2}$ : Carbon dioxide; DBP: Diastolic blood pressure; OHS: Obesity-hypoventilation syndrome; OSA: Obstructive sleep apnea; SBP: Systolic blood pressure; StHCO3: Bicarbonate

\section{Acknowledgements}

The authors would like to express their gratitude to Dr. Jörg Hermann Peter and Dr. Thomas Podszus for initiation of the study cohort.

\section{Funding}

The study was supported by the German Research Foundation (DFG), the German Ministry for Education and Science (BMBF) and Swedish Heart and Lung Foundation.

\section{Availability of data and materials}

The datasets used and/or analysed during the current study available from the corresponding author on reasonable request.

\section{Authors' contributions}

DZ, DE and JH contributed to conception and design, analysis and interpretation of data, and the writing of the manuscript. LG contributed to conception and design, acquisition, analysis and interpretation of data, and the writing of the manuscript. HS and TP contributed to acquisition and interpretation of data, and critical review the manuscript. All authors read and approved the final manuscript.

\section{Competing interests}

The authors declare that they have no competing interests.

\section{Consent for publication}

Not applicable.

\section{Ethics approval and consent to participate}

All patients gave their written consent for participation in the study according to the contemporary regulations for medical research (1989-1992) at the Marburg University, Marburg, Germany.

\section{Publisher's Note}

Springer Nature remains neutral with regard to jurisdictional claims in published maps and institutional affiliations.

\section{Author details}

${ }^{1}$ Center for Sleep and Vigilance Disorders, Department of Internal Medicine and Clinical Nutrition, Sahlgrenska Academy, University of Gothenburg, Medicinaregatan 8B, Box 421 SE-40530 Gothenburg, Sweden. ${ }^{2} J o h n s ~ H o p k i n s$ Sleep Disorders Center, Division of Pulmonary and Critical Care Medicine, Johns Hopkins University, Baltimore, Maryland, USA. ${ }^{3}$ Interdisciplinary Center of Sleep Medicine, Charité-Universitätsmedizin Berlin, Berlin, Germany. ${ }^{4}$ International Clinical Research Center, St. Anne's University Hospital Brno, Brno, Czech Republic.

\section{Received: 29 November 2016 Accepted: 8 June 2017}

\section{Published online: 28 June 2017}

\section{References}

1. Dempsey JA, Veasey SC, Morgan BJ, O'Donnell CP. Pathophysiology of sleep apnea. Physiol Rev. 2010;90:47-112.

2. Maren TH. Carbonic anhydrase: chemistry, physiology, and inhibition. Physiol Rev. 1967;47:595-781.

3. Wang T, Eskandari D, Zou D, Grote L, Hedner J. Increased Carbonic Anhydrase Activity is Associated with Sleep Apnea Severity and Related Hypoxemia. Sleep. 2015;38:1067-73.

4. McNicholas WT, Bonsigore MR. Sleep apnoea as an independent risk factor for cardiovascular disease: current evidence, basic mechanisms and research priorities. Eur Respir J. 2007;29:156-78.

5. Parati G, Lombardi C, Hedner J, Bonsignore MR, Grote L, Tkacova R, Levy P, Riha R, Bassetti C, Narkiewicz K, et al. Position paper on the management of patients with obstructive sleep apnea and hypertension: joint recommendations by the European Society of Hypertension, by the European Respiratory Society and by the members of European COST
(COoperation in Scientific and Technological research) ACTION B26 on obstructive sleep apnea. J Hypertens. 2012;30:633-46.

6. Cooper VL, Pearson SB, Bowker CM, Elliott MW, Hainsworth R. Interaction of chemoreceptor and baroreceptor reflexes by hypoxia and hypercapnia - a mechanism for promoting hypertension in obstructive sleep apnoea. J Physiol. 2005;568:677-87.

7. Pickkers P, Garcha RS, Schachter M, Smits P, Hughes AD. Inhibition of carbonic anhydrase accounts for the direct vascular effects of hydrochlorothiazide. Hypertension. 1999;33:1043-8.

8. Parati G, Revera M, Giuliano A, Faini A, Bilo G, Gregorini F, Lisi E, Salerno S, Lombardi C, Ramos Becerra CG, et al. Effects of acetazolamide on central blood pressure, peripheral blood pressure, and arterial distensibility at acute high altitude exposure. Eur Heart J. 2013:34:759-66.

9. Eskandari D, Zou D, Karimi M, Stenlof K, Grote L, Hedner J. Zonisamide reduces obstructive sleep apnoea: a randomised placebo-controlled study. Eur Respir J. 2014:44:140-9.

10. Latshang TD, Nussbaumer-Ochsner Y, Henn RM, Ulrich S, Lo Cascio CM Ledergerber B, Kohler M, Bloch KE. Effect of acetazolamide and autoCPAP therapy on breathing disturbances among patients with obstructive sleep apnea syndrome who travel to altitude: a randomized controlled trial. JAMA. 2012;308:2390-8.

11. Grote L, Ploch T, Heitmann J, Knaack L, Penzel T, Peter JH. Sleep-related breathing disorder is an independent risk factor for systemic hypertension. Am J Respir Crit Care Med. 1999;160:1875-82.

12. Arterial hypertension. Report of a WHO expert committee. World Health Organization technical report series 1978;628:7-56.

13. Stoohs R, Guilleminault C. MESAM 4: an ambulatory device for the detection of patients at risk for obstructive sleep apnea syndrome (OSAS). Chest. 1992;101:1221-7.

14. Bearpark H, Elliott L, Grunstein $\mathrm{R}$, Cullen S, Schneider $\mathrm{H}$, Althaus W, Sullivan C, Snoring and sleep apnea. A population study in Australian men. Am J Respir Crit Care Med. 1995:151:1459-65.

15. Roos M, Althaus W, Rhiel C, Penzel T, Peter JH, von-Wichert P. Comparative use of MESAM IV and polysomnograph in sleep-related respiratory disorderes. Pneumologie. 1993;47:112-8.

16. Bingol Z, Pihtili A, Cagatay P, Okumus G, Kiyan E. Clinical predictors of obesity hypoventilation syndrome in obese subjects with obstructive sleep apnea. Respir Care. 2015:60:666-72.

17. Manuel AR, Hart N, Stradling JR. Is a raised bicarbonate, without hypercapnia, part of the physiologic spectrum of obesity-related hypoventilation? Chest. 2015;147:362-8.

18. Norman RG, Goldring RM, Clain JM, Oppenheimer BW, Charney AN, Rapoport DM, Berger Kl. Transition from acute to chronic hypercapnia in patients with periodic breathing: predictions from a computer model. J Appl Physiol. 2006;100:1733-41.

19. Kittivoravitkul P, Kaw R, Hatipoglu U, Wang L, Aboussouan LS. Determinants of Wake Pco2 and Increases in Wake Pco2 over Time in Patients with Obstructive Sleep Apnea. Ann Am Thorac Soc. 2016;13:259-64.

20. Chung F, Chau E, Yang Y, Liao P, Hall R, Mokhlesi B. Serum bicarbonate leve improves specificity of STOP-Bang screening for obstructive sleep apnea. Chest. 2013;143:1284-93.

21. Juel C, Lundby C, Sander M, Calbet JA, Hall G. Human skeletal muscle and erythrocyte proteins involved in acid-base homeostasis: adaptations to chronic hypoxia. J Physiol. 2003;548:639-48,

22. Javaheri S. Acetazolamide improves central sleep apnea in heart failure: a double-blind, prospective study. Am J Respir Crit Care Med. 2006;173:234-7.

23. Raurich JM, Rialp G, Ibanez J, Llompart-Pou JA, Ayestaran I. Hypercapnic respiratory failure in obesity-hypoventilation syndrome: $\mathrm{CO}(2)$ response and acetazolamide treatment effects. Respir Care. 2010;55:1442-8.

24. Mandel El, Forman JP, Curhan GC, Taylor EN. Plasma bicarbonate and odds of incident hypertension. Am J Hypertens. 2013;26:1405-12.

25. Luft FC, Zemel MB, Sowers JA, Fineberg NS, Weinberger MH. Sodium bicarbonate and sodium chloride: effects on blood pressure and electrolyte homeostasis in normal and hypertensive man. J Hypertens. 1990:8:663-70.

26. He FJ, Marciniak M, Carney C, Markandu ND, Anand V, Fraser WD, Dalton RN, Kaski JC, MacGregor GA. Effects of potassium chloride and potassium bicarbonate on endothelial function, cardiovascular risk factors, and bone turnover in mild hypertensives. Hypertension. 2010:55:681-8.

27. Santos A, Martins MJ, Guimaraes JT, Severo M, Azevedo I. Sodium-rich carbonated natural mineral water ingestion and blood pressure. Rev Port Cardiol. 2010;29:159-72. 
28. Gold AR, Schwartz AR, Wise RA, Smith PL. Pulmonary function and respiratory chemosensitivity in moderately obese patients with sleep apnea. Chest. 1993;103:1325-9.

29. Pickkers $P$, Hughes AD, Russel FG, Thien T, Smits P. In vivo evidence for $\mathrm{K}(\mathrm{Ca})$ channel opening properties of acetazolamide in the human vasculature. Br J Pharmacol. 2001;132:443-50.

30. Aamand R, Dalsgaard T, Jensen FB, Simonsen U, Roepstorff A, Fago A. Generation of nitric oxide from nitrite by carbonic anhydrase: a possible link between metabolic activity and vasodilation. Am J Physiol Heart Circ Physiol. 2009;297:H2068-2074.

31. Lord S, Sawyer B, O'Connell D, King M, Pond D, Eyland A, Mant A, Holland JT, Hensley MJ, Saunders NA. Night-to-night variability of disturbed breathing during sleep in an elderly community sample. Sleep. 1991;14:252-8.

32. Frassetto LA, Nash E, Morris Jr RC, Sebastian A. Comparative effects of potassium chloride and bicarbonate on thiazide-induced reduction in urinary calcium excretion. Kidney Int. 2000;58:748-52.

Submit your next manuscript to BioMed Central and we will help you at every step:

- We accept pre-submission inquiries

- Our selector tool helps you to find the most relevant journal

- We provide round the clock customer support

- Convenient online submission

- Thorough peer review

- Inclusion in PubMed and all major indexing services

- Maximum visibility for your research

Submit your manuscript at www.biomedcentral.com/submit
Biomed Central 